\title{
O SIGNO JUSTIÇA: arena de (d)e(s)ncontro de sentidos
}

\author{
llderlândio Assis de Andrade Nascimento \\ Universidade Federal do Rio Grande do Norte \\ https://orcid.org/0000-0002-3654-614X \\ Antonio Flávio Ferreira de Oliveira \\ Universidade Estadual da Paraíba \\ https://orcid.org/0000-0002-9758-270X
}

\section{RESUMO:}

Neste trabalho, analisamos rediscursivizações do símbolo da justiça em charges que circulam na internet e que foram produzidas entre os anos de 2017 e 2019 , tendo em vista o cenário de críticas à justiça brasileira, mais precisamente, as críticas tecidas contra alguns eventos ocorridos na esfera jurídica. Para isso, dialogamos com a perspectiva enunciativa do Círculo de Bakhtin, especialmente Bakhtin (2011) e Volóchinov (2017). Assumimos que o símbolo da justiça se constitui signo ideológico, pois é arena de encontro e desencontro de sentidos. As charges analisadas mostram como os autores trabalham a ressignificação dos sentidos de justiça, materializando pontos de vista, posições valorativas diante do atual cenário jurídicopolítico brasileiro. Por outro lado, os enunciados também desvelam outros discursos, mais precisamente, quanto à figura feminina. Assim, constatamos que as críticas tecidas à justiça utilizavam a figura feminina de forma sensualizada, como garota de programa, como mulher que vende o corpo, como safada. O corpo feminino aparece sempre como objeto à venda e que tem na figura masculina um possuidor, um dono. Desse modo, é possível perceber como o discurso machista atravessa as charges, mesmo que de forma inconsciente, revelando o quanto esse problema se encontra nas estruturas sociais e que afloram em discursos como os analisados. 
PALAVRAS-CHAVE: Signo justiça. Ideologia e sentidos. Crítica à justiça. Corpo feminino.

\section{THE JUSTICE SIGN: \\ the place of meeting and mismatching}

\section{ABSTRACT:}

In this work, we analysed justice symbols (re)discursivazation in charges that circle on Internet produced during the years of 2017 and 2019, focusing on criticals to Brazilian Justice, preciselly, those ones against some events ocurred in juridical spheres. Thus, we dialogue with Bakhtin's Circle enunciative perspective, especially Bakhtin (2011) and Volóchinov (2017). Assuming that the justice symbol constitute as ideological sign, because it is the place of meeting of senses. The analysed materials showed how the authors work the (re)signification of justice materializing ponto $f$ views, valorative positions before the current juridical, political brazilian scenario. Although, the utterances also reveal other discourses, preciselly in terms off emale figure. In this sense, we noted that the criticals to the justice used the female figure in relation to sensualization, as a prostitute, a woman that sells her body as a naughty. The female body seems always as an object to be sold and, in a male figure, has na owner. In this regard, it is possible to percept how male discourse crossed the charges, even if, insconsciently, it reveals the how much this problem is represented in the social strutures becoming in discourse as the ones analysed.

KEYWORDS: Justice sign. Ideology and senses. Criticals to justice. Female body.

\section{Introdução}

Neste trabalho, compreendemos a construção ideológicoaxiológica do símbolo da Justiça brasileira como um signo ideológico. Enquanto materialidade, esse signo é composto por três elementos essenciais, a saber, uma mulher com os olhos vendados, 
com uma espada na mão direita e uma balança na mão esquerda, representando o nível de igualdade. Nesse sentido, a relação desse conjunto de elementos corrobora a ideia de uma instância onde se luta, de modo igualitário e isonômico, para se reparar um dano causado a outrem.

Ao comentar os significados dos elementos que compõem o símbolo da justiça, Cirlot (1984) diz que a balança é a equação entre castigo e culpa, um produto semiótico bem adequado para demonstrar que, na instância jurídica, a deliberação do poder é moderada, sobretudo, pelo fato de transparecer a impressão de que a justiça é uma forma de aplicação da medida razoável de o Estado resolver os litígios humanos que são colocados à disposição da corte estatal. Concordando com a relação de sentido da balança, a venda nos olhos da mulher expressa a ideia de imparcialidade e sabedoria no que concerne ao modo de julgar.

Chevalier (2002) explica que a espada expressa a ideia de que existe o Estado com a virtude e o poder de ação coercitiva; como pontua o autor, essa ideia de poder estatal se ergue sob dois pilares consolidantes, a saber, o poder de destruição e o poder de construção. No que concerne ao pensamento de Becker (1999), o signo ideológico da espada representa um elemento do poder estatal que tem por finalidade a luta contra a injusta, a maleficência e a ignorância para positivar a instituição da paz e da justiça.

No entanto, acontecimentos no mundo político-econômico têm feito surgir enunciados que se rebelam contra esses sentidos estabilizados de justiça. O símbolo da justiça tem sido objeto de ressignificações, de contradiscursos. Enunciados têm surgido como negação a esse sentido de justiça. Com isso, neste trabalho, queremos analisar como o símbolo da justiça tem sido (re)discusivizado, adquirindo sentidos outros. Assim, compreenderemos o símbolo da justiça enquanto signo ideológico que reflete e refrata sentidos. Para isso, analisaremos charges produzidas entre os anos de 2017 e 2019, tendo em vista o cenário de críticas à justiça brasileira, mais precisamente, as críticas tecidas contra alguns eventos ocorridos na esfera jurídica.

Para isso, dialogamos com os estudos oriundos do Círculo de Bakhtin, principalmente as noções de enunciado concreto, dialogismo, ideologia. Portanto, antes de analisarmos os enunciados selecionados, desenvolveremos, na próxima seção, uma discussão 
acerca da proposta teórico-metodológica da Análise Dialógica do Discurso (ADD), recuperando noções fundamentais presentes nos escritos do Círculo de Bakhtin.

\section{Análise Dialógica do Discurso: conceitos essenciais}

A Análise Dialógica do Discurso, doravante ADD, constitui um modo analítico de olhar, criticamente, para um fato discursivo em razão de vários elementos que determinam sua existência, como por exemplo, o lugar onde surgiu esse fato, o tempo, o espaço, quem são os sujeitos envolvidos, a necessidade comunicativa que gerou esse fato, bem como o modo entoacional e organizacional como o sujeito enunciador expressou esse fato. Nessa modalidade de análise, procura-se observar o complexo de elementos valorativos que estão, implicitamente, do lado exterior da linguagem, sobre tudo, aqueles que são compartilhados pelos sujeitos envolvidos no acontecimento discursivo.

A ADD é estabelecida pelo fundamento teórico e metodológico da Teoria Dialógica da Linguagem - TDL - , uma teoria que se firma na ideia de compreender a língua e a linguagem como os elementos imprescindíveis para a organização da sociedade, principalmente pela razão de serem usadas como um sistema flexível de signos ideológicos e o material da criação humana (VOLÓCHINOV, 2017). Vale ressaltar que essa concepção de língua e linguagem compreende a instância e o modus operandi da razão de ser, existir e (re)criar do ser humano.

$\mathrm{Na}$ e pela linguagem se estabelece o vir a ser do modo como se concebe a realidade como um conjunto de realidades, o mundo como um conjunto de mundos e os sujeitos como seres constituídos biológica e socialmente na ordem física e histórica do mundo. Sendo assim, língua e linguagem operam para dar razão de existência ao conjunto de pontos de vista que compreendem o conjunto imaginário ideológico de uma comunidade.

Considerando essa concepção de língua e linguagem, devemos também apontar para dois grandes elementos que compreendem a realização e a concretização de seus usos, a saber, a concepção de discurso e de enunciado. Por sua vez, discurso, como 
postula Bakhtin (2010 A, p. 207) institui “a língua em sua integridade concreta e viva". Nesse sentido, por um lado, cabe dizer que a ideia de concretização e de vida como elementos constitutivos da língua corrobora a noção de imbricamento de razão, sentimento, historicidade, axiologia, cultura, ideologia, economia, entre outros que se irrompem do todo que constitui as marcas de espaço e tempo. Por outro lado, o enunciado caracteriza-se por um modo típico de representar e organizar a construção do uso vivo da língua pela integração de sua forma material e ideológica, bem como o "produto" da criação verbal ou semiótica do sujeito em uma dada circunstância social. Logo, o discurso representa o modo de organização social, histórica e cultural da criação/existência do conjunto de ideias de uma coletividade, enquanto o enunciado representa a manifestação concreta do conjunto dessas ideias em relação ao grau de hierarquia entre os sujeitos.

A compreensão de discurso e enunciado é relevante para o entendimento de gêneros discursivos, que, como entendeu Bakhtin (2011, p. 262), compreendem "tipos relativamente instáveis de enunciados", isto é, modos de organização e expressão dos modos de organização social da criação ideológica de uma coletividade e a organização da materialização verbal e imagética dos pontos de sujeitos em situação de interação. Para tanto, como afirma o autor, para se comunicar, é preciso considerar a importância de vários elementos, como por exemplo, as representações ideológicas oriundas das relações subjetivas das várias esferas sociais, a função de cada sujeito nos campos sociais e as necessidades de comunicação que existem em decorrência das necessidades de ação desses sujeitos. No entendimento da TDL, é só através dos gêneros do discurso que os sujeitos podem e devem expressar-se como sujeitos de uma dada coletividade social para realizarem suas ações discursivas e seus modos de criar, representar, interpretar e compreender o mundo.

Em termos mais práticos, o gênero discursivo charge representa um modo de criação, de organização, de expressão e de materialização da comunicação de sujeitos sociais nas esferas midiáticas, principalmente para demonstrar pontos de vista críticos em relação a um fato social, político ou de outro domínio ideológico. Conforme assevera Costa (2004), o gênero charge está relacionado à representação de traços exagerados do etos de alguém, bem como 
para tratar de "uma ilustração ou desenho humorístico, com ou sem legenda ou balão, veiculado pela imprensa, que tem por finalidade satirizar e criticar algum acontecimento do momento" (COSTA, 2009 , p. 60). Sendo assim, compreendemos que é por meio da charge que se podem materializar fatos sociais, políticos ou de outras naturezas, de modo que se estabeleça uma adequação entre a construção estilístico-temático-composicional e uma possível efetivação desse gênero para uma comunicação social específica.

De modo particular, as ações discursivas do sujeito compreendem um conjunto de ações que, antes de serem expressas no mundo físico, são ações pensadas e dialogadas no mundo das ideias, isto é, são ações que compreendem um conjunto de atos que, na compreensão de Bakhtin (2010b), como afirma Ponzio (2010, p. 9), são passos "atos de pensamento, de sentimento, de desejo", a criação e construção de tudo o que existe no mundo individual em razão do tudo o que existe nas consciências dos outros. Ainda como entende Ponzio (2010, p. 9-10), o ato significa "um passo, como iniciativa, movimento, ação arriscada, tomada de posição". Como entende Nascimento (2015), a construção do ato compreende a autoria do modo particular e individual que o sujeito tem de orquestrar, em sua própria voz, vozes dissonantes e consoantes, isto é, um conjunto orquestrado pelo todo de vozes que compõem o imaginário da coletividade humana.

Pensando o ato como um elemento categórico no bojo da ADD, podemos afirmar que é por ele que a dialogia se instaura nas práticas discursivas, pois, como postula Bakhtin (2017), a palavra compreende o lugar do encontro das consciências de outrem na consciência de um sujeito e, de modo particular, é na palavra que o conjunto ideológico se instaura para dizer os diferentes modos de apreensão das realidades. Como defende Volóchinov (2017, p. 95, grifo nosso), o signo é o lugar de atuação dos diversos pontos de vista sociais, o que institui a "compreensão de um signo [que] ocorre na relação deste com outros signos já conhecidos", e é desse modo que a dialogia se estabelece na cadeia ideológica no ou pelo encontro de várias consciências. Desse modo, o sujeito se faz autor do seu dizer, assumindo um ponto de vista em relação aos pontos de vista dos outros. Na TDL, isso é compreendido como o modo que o sujeito tem de expressar, por um ângulo particular, sua subjetividade no dizer, bem como criar, pela determinação de uma dada situação, 
seu modo particular de interpretar, compreender e expressar o mundo, como entende Oliveira (2015), isso seria a chamada entonação avaliativa.

Sendo assim, ao assumir a responsabilidade da entonação do seu dizer, o sujeito mobiliza um conjunto de vozes sociais nas quais se impregnam tonalidades históricas, sociais, ideológicas, culturais, axiológicas, políticas, econômicas, jurídicas etc. São essas vozes que refletem e refratam os sentidos propícios para uma enunciação particular, sobretudo considerando o todo de elementos que compõe a situação discursiva no que diz respeito ao sujeito a quem se dirige a comunicação (o outro), as necessidades de dizer do sujeito (in)locutor, as condições espaço-temporais etc. Essas vozes se imbricam e se impregnam na materialidade enunciativa unindo-se e integrando-se no todo que dá sentido ao enunciado. Em outras palavras, dizemos que é por causa dessas vozes que a materialidade transpõe a apenas base de sentido linguístico ou imagético, fazendo com que o todo externo à linguagem se (re)crie no uso e pelo uso da linguagem.

Dentre os muitos conceitos que constituem a ADD, são estes que movimentamos para sustentar a análise dos fatos discursivos no corpus escolhido. Através das lentes desses conceitos, observamos os fatos discursivos em razão de perceber como a TDL fundamenta o olhar científico para a investigação de acontecimentos sociais.

\section{0 signo Justiça: arena de (d)e(s)ncontro de sentidos}

Os enunciados analisados a seguir trazem em sua constituição a ressignificação do símbolo da justiça. Ou seja, as charges operam uma reconfiguração na materialidade do símbolo, agregando novos sentidos, novos pontos de vista, novas valorações. Ademais, cabe destacar as valorações em torno da figura feminina, pois os discursos críticos que se voltam contra as noções estabilizadas de justiça deixam aparecer outros sentidos, voltados para a figura da mulher e seu corpo. Assim, o signo da justiça se transforma em uma arena de encontro e desencontro de sentidos. 


\section{Descrição da charge correspondente ao Enunciado $1^{1}$}

$\mathrm{Na}$ charge, há duas personagens, uma representando o símbolo da justiça e a outra representando um possível político/parlamentar. Quanto à primeira, tem-se a deusa da justiça, a mulher de olhos vendados, segurando a balança com a mão esquerda e, com a direita, segurando a espada erguida para cima. A mulher parece ser de cor clara; usa um vestido longo sem mangas, um sapato preto de saltos altos e uma meia arrastão; no lado esquerdo, nas proximidades do seio esquerdo, usa um crachá com as iniciais TJ - RS. No caso da segunda personagem, tem-se a mão de um homem branco, que usa uma camisa branca de mangas compridas e um terno preto. Esse homem parece ser um político que está levantando o lado esquerdo do vestido da deusa, e está colocando dinheiro dentro de sua meia. $\mathrm{O}$ todo da imagem indica a cena de um político colocando dinheiro na peça de roupa íntima de uma profissional do sexo.

Confira a charge em: <http://in-justicabrasileira.blogspot.com/p/charges.html $>$.

No Enunciado 1, o símbolo da justiça é ressignificado a partir da inserção de novos símbolos. A imagem da charge ganha elementos que vestem o corpo feminino, como o vestido e a meia arrastão. Além disso, uma mão masculina coloca dinheiro na peça de roupa íntima da mulher, denotando um ato de pagamento e compra de um serviço. Ou seja, a charge visa tecer uma crítica ao sistema judiciário, apontando suas corrupções. Mais precisamente, a charge denuncia as negociatas que ocorrem entre grandes detentores do capital financeiro e a justiça. Nesse caso, a crítica ganha um direcionamento, pois, junto ao peito da imagem da justiça, aparece a seguinte informação "TJ-RS".

A charge coloca em questão novos sentidos, ou seja, novas valorações são atribuídas ao signo justiça. Esse signo refrata o sentido de uma justiça equilibrada, igual para todos, como definem Chevalier (2002) e Becker (1999), constrindo os sentidos de uma justiça que se vende, que negocia, que é parcial.

\footnotetext{
${ }^{1}$ Optamos por fazer a descrição das charges, visto que não conseguimos contactar os autores para solicitar a permissão de uso nas análises do artigo.
} 
Ao mesmo tempo em que constrói a crítica, a charge também, consciente ou inconscientemente, é perpassada por outros discursos, outras vozes ideológicas. Nesse caso, constatamos um discurso sobre o corpo feminino, pois, para fazer sentido, a charge recupera sentidos estereotipados acerca da mulher. Assim, a figura feminina que vende seu corpo por dinheiro aparece na construção de sentidos da charge. Portanto, tal discurso faz ouvir discursos que colocam o corpo da mulher como um objeto que se pode possuir, numa relação capitalista de compra e venda.

Na mesma linha ideológica, vejamos o enunciado 2:

\section{Descrição da charge correspondente ao Enunciado 2}

Duas personagens compõem a charge (um homem e uma mulher) que parecem estar em um pátio próximo ao Palácio do Planalto. A primeira personagem parece representar a estátua de uma prostituta sentada em uma base de concreto. Essa mulher usa uma venda preta nos olhos, batom preto, uma blusa escura preta, uma meia arrastão preta, um chicote preto e um par de botas pretas. A mulher, mesmo sentada, tem tamanho superior ao da outra personagem. A segunda personagem simboliza um homem de meia idade, baixo, de óculos e careca. Esse homem é de cor branca; está vestindo um terno marrom-claro, segura, na mão direita, uma pasta cheia de dinheiro; com a mão esquerda, está oferecendo dinheiro para a mulher, dizendo: MOÇA, QUANTO É O "PROGRAMA"? Na cena, parece haver a representação do diálogo de um político com uma estátua (a mulher que, possivelmente, simboliza a justiça.

Confira essa charge em: <https://br.pinterest.com/pin/454793262359319700>

No Enunciado 2, de forma mais explícita, a crítica à justiça é feita a partir da imagem de uma mulher que "faz programa". Na charge, aparece a figura de um homem (um político) com uma mala cheia de dinheiro e que faz a seguinte proposta: "Moça, quanto é o 'programa'?". A imagem símbolo da justiça é construída usando trajes sensuais que retomam práticas das assim popularmente denominadas "mulheres de programa". Como bem nos faz ver Volóchinov (2017, p. 91 grifo do autor), "tudo o que é ideológico possui uma significação: ele representa e substitui algo encontrado 
fora dele, ou seja, ele é um signo. Onde não há signo também não há ideologia".

Na charge em questão, os signos ideológicos direcionam para duas realidades discursivas que aparecem na construção de sentidos. A primeira diz respeito à construção de uma crítica ao sistema judiciário brasileiro, principalmente na sua relação promíscua com políticos corruptos. A segunda realidade surge de forma mais velada, pois aparece como discurso subentendido, subjacente, a saber, a presença de um discurso que inferioriza o trabalho das profissionais do sexo.

Na próxima charge, mais uma vez, essa relação entre justiça e profissionais do sexo (popularmente, "mulheres de programa") aparece em tela.

\section{Descrição da imagem correspondente ao Enunciado 3}

$\mathrm{Na}$ charge, existem duas personagens: um garoto e uma mulher que estão conversando em frente ao prédio do Supremo Tribunal Federal. O garoto parece estar passando por ali. É um garoto branco; usa um boné marrom colocado na cabeça com a aba para trás, uma camisa cinza e uma bermuda de tonalidade verde; o garoto está com as mãos no bolso e olhando com os olhos "arregrados" para a mulher. A mulher está em pé olhando para o garoto. Na cabeça, ela usa um gorro de tonalidade rosa escuro; usa um tipo de vestido macaquinho-espartilho que deixa amostra os seios avantajados; meias arrastão com ligas e sapatos de saltos altos de cor vermelha. Está com a mão esquerda (apoiada numa espada) próximo à cintura, e, com a mão direita, ela roda a bolsinha. A mulher parece ter o rosto "feio", isto é, que não está adequado ao padrão para beleza de rostos modernos. A mulher está em pé sobre uma base de concreto, que contém a sigla STF.

Confira a charge em: $<$ http://in-justicabrasileira.blogspot.com/p/charges.html $>$

No Enunciado 3, o termo "justiça" aparece no enunciado verbal atribuído à personagem que simboliza a justiça " $E$ aí, garotão? Procurando uma justiça bem safada?". Além desses elementos verbais, a charge apresenta uma imagem estereotipada da profissional do sexo. Isso é percebido pelas vestes e pelo gesto de "rodar a bolsa", sendo esse um gesto-símbolo desse grupo de mulheres. Cabe lembrar que esses elementos constituem fenômenos 
ideológicos, pois, conforme Volóchinov (2017, p. 94), “qualquer fenômeno ideológico sígnico é dado em algum material: no som, na massa física, na cor, no movimento do corpo e assim por diante". Desse modo, o signo "rodar a bolsa", que aparece na charge, é um signo território interindividual, pois é compartilhado socialmente.

No enunciado a seguir, temos a mobilização de fenômenos ideológicos, mais precisamente, os símbolos da justiça, na construção de uma crítica aos juízes e profissionais da esfera jurídica que são responsáveis por emitir julgamentos.

\section{Descrição da charge correspondente ao Enunciado 4}

A imagem é composta por três personagens, um homem, uma mulher e uma cachorrinha. O homem (que diz: "não tenho prova, mas tenho convicção") está sentado em um banco, usando óculos escuros e vestido com uma toga preta. A mulher (que diz: "ai, você tira minha visão!") está sentada no colo do homem (que segura seus seios), usa uma venda nos olhos, está com um vestido sensual que deixa à mostra sua coxa direita, entre suas pernas, está uma espada e, com a mão esquerda, segura uma balança. A cachorrinha (que diz: “Cega, não! Sem vergonha!”) parecer estar indignada por ver a cena.

Confira a charge em: < https://luizmuller.com/2016/09/16/a-justica-e-cega $>$

O Enunciado 4 critica personagens da esfera jurídica que julgam e condenam sem as provas necessárias para tal, como se constata no dizer atribuído ao representante dos juristas: "Não tenho prova, mas tenho convicção!". Em resposta a esse diálogo, à justiça é atribuído o seguinte dizer: "Ai, você tira a minha visão!". A visão imparcial da justiça, que é simbolizada pela venda nos olhos, é ressignificado, pois ganha um sentido oposto, ou seja, a justiça é criticada por tomar partido, assumir uma posição ideológica, ser parcial nos julgamentos. Essa crítica à justiça aparece de forma explícita, quase como um rótulo do todo do enunciado, no dizer atribuído a uma terceira personagem da charge, um cachorro, quando diz: “Cega, não! Sem vergonha!".

Cabe destacar a tonalidade das falas das personagens. Todas as frases são finalizadas com ponto de exclamação. Essa escolha marca a expressividade das vozes na charge, pois, de certa forma, 
são vozes sociais refratadas que representam pontos de vista, ideologias e valorações.

Quanto à discursivização da mulher, percebemos que o corpo feminino aparece sensualizado e é tocado/violado pela personagem masculina. Essa construção imagética juntamente com o elemento verbal "sem vergonha" rotulam a mulher, colocando-a numa posição de inferioridade, pois seu corpo é objetificado, sem contar que é a figura feminina o elemento negativo da charge.

Ao construírem sentido a partir da tessitura entre a crítica à esfera jurídica e ao discurso em torno da figura feminina, as charges tendem a construírem uma imagem erotizada do corpo feminino. Isso fica bem explícito em charges como a seguinte:

\section{Descrição da charge correspondente ao Enunciado 5}

A charge apresenta duas personagens, uma mulher e um homem. O homem está usando sapatos sociais pretos, calça social preta, uma camisa branca, de mangas longas (que está aberta) e uma gravata solta em volta do pescoço. Esse homem está sentado numa cadeira de madeira, com o assento e o encosto revestidos de couro vermelho. Ele parece estar bem entusiasmado. A mulher (que: com os olhos vendados, usa um vestido sensual [que deixa à mostra suas coxas, nádegas e seios], segura uma balança com a mão direita) parece estar gostando do que está fazendo. A cena deixa presumida a configuração de um ato sexual.

Confira a charge em: <https://www.esmaelmorais.com.br/2017/07/justicasegundo-as-redes-sociais>

No Enunciado 5, a crítica que se faz a justiça evoca a imagem de uma mulher com as partes intimas expostas. Ela representa o símbolo da justiça em posição erótica. Assim, critica-se uma justiça que é adúltera, que se prostitui, que se vende. São sentidos que surgem em reação aos sentidos naturalizados acerca da justiça.

Ao mesmo tempo, o enunciado traz para a cena enunciativa a erotização da imagem feminina. O corpo que representa a mulher é um corpo sarado, definido, cheio de curvas, perfeito, segundo os padrões das propagas das academias de musculação. Desse modo, o corpo feminino é idealizado e posto como elemento de sensualidade. 


\section{Descrição da charge correspondente ao Enunciado 6}

A charge apresenta uma mulher robusta, com olhos vendados, segurando uma balança com a mão direita e uma espada com a mão esquerda, com corpo inclinado para frente, apoiando-se sobre a espada, mostrando a parte superior das nádegas (a imagem destaca a abertura das nádegas); logo atrás da mulher, mirando suas nádegas expostas, um homem de estatura média, branco, careca, usando terno, diz: DEVE SER A TAL BRECHA DA LEI.

Confira a charge em: <http://politizandoam.com.br/2019/07/17/artigo-aos-amigosos-favores-aos-inimigos-a-lei/>

O enunciado 6 em análise traz para a cena discursiva o fato de existir na lei as chamadas brechas. Essas brechas costumam ser lugares de escape encontrados por advogados que cobram grandes quantias de dinheiro para livrar figuras políticas e/ou empresariais de cumprir determinada pena. Esse discurso é materializado no dizer atribuído a uma das personagens que, diante da justiça, diz: "Deve ser a tal brecha da lei.". A charge utiliza o corpo feminino para retomar esse discurso de forma crítica e humorística. Para isso, ocorre a exposição de parte das nádegas do corpo feminino, ou seja, a exposição das nádegas feminina é utilizada para causar humor e, ao mesmo tempo, criticar a justiça.

Ao mesmo tempo em que a crítica à justiça é feita, mais precisamente, à facilidade que a justiça oferece aos advogados para encontrar brechas na lei, a charge é construída sob outro discurso, a saber, o discurso da erotização do corpo feminino e, por que não dizer, o da condenação desse corpo, pois seus traços físicos são mobilizados para representar aquilo que é errado, proibido, corrupto, ilegal, condenável.

Portanto, diante das análises empreendidas, percebemos que a imagem da mulher como representação da justiça costuma aparecer relacionada ao sexo, aos atos libidinosos, à prostituição, à violação do corpo, ao estrupo. Nesses casos, a figura masculina aparece exercendo o papel central, cabendo à mulher o papel inferior, pois seu corpo é discursivizado a partir de valorações negativas: corrupção, prostituição, safadeza etc. 


\section{Considerações finais}

Neste trabalho, voltamos nosso olhar para (re)discursivizações do símbolo da justiça. Para isso, analisamos charges produzidas entre os anos de 2017 e 2019, tendo em vista o cenário de críticas à justiça brasileira, mais precisamente, as críticas tecidas contra alguns eventos ocorridos na esfera jurídica. Assumimos que o símbolo da justiça se constitui signo ideológico, pois é arena de encontro e desencontro de sentidos. Para a análise dos enunciados, tomamos como referência a perspectiva dialógica da linguagem oriunda do Círculo de Bakhtin, principalmente as noções de enunciado concreto, dialogismo, ideologia.

As charges analisadas mostram como os autores trabalham a ressignificação dos sentidos de justiça. Assim, as charges materializam pontos de vista, posições valorativas diante do atual cenário jurídico-político brasileiro. As charges são campos de lutas de sentidos, são enunciados que surgem como reação aos problemas jurídicos que têm causado instabilidade jurídica no Brasil. Desse modo, as charges se configuram como discursos de denúncia contra as mais recentes injustiças causadas pela justiça. Esse discurso de reação ocorre na contra-palavra formada a partir dos elementos do próprio símbolo da justiça. Esse signo ideológico passa a refletir a e refratar novos e antagônicos sentidos.

Por outro lado, os enunciados também desvelam outros discursos, mais precisamente, quanto à figura feminina. Isso se deve ao fato de que o símbolo da justiça ser uma figura feminina. No entanto, o que nos interessou foi o modo como a figura feminina aparece discursivizada. Assim, constatamos que as críticas tecidas à justiça utilizavam a figura feminina de forma sensualizada, como garota de programa, como mulher que vende o corpo, como safada. Em todos os enunciados o corpo feminino esteve em evidência como algo causador do riso, do humor.

Esse corpo feminino, cabe pontuar, apareceu sempre como objeto à venda e que tem na figura masculina um possuidor, um dono. Desse modo, é possível perceber como o discurso machista atravessa as charges, mesmo que de forma inconsciente, revelando o quanto esse problema se encontra nas estruturas sociais e que afloram em discursos como os analisados. 


\section{REFERÊNCIAS}

BAKHTIN, Mikhail Mikhailovich. Estética da criação verbal. São Paulo: Martins Fontes, 2011.

BAKHTIN, Mikhail Mikhailovich. Problemas da poética de Dostoievski. Rio de Janeiro: Forense Universitária, 2010 a.

BAKHTIN, Mikhail Mikhailovich. Para uma Filosofia do Ato Responsável. São Paulo: Pedro \& João Editores, 2010 b.

BECKER, Udo. Dicionário de Símbolos. Trad.: Edwino Royer. São Paulo: Paulus, 1999.

BIEDERMANN, Hans. Cegueira. In:. Dicionário ilustrado de símbolos com mais de $\mathbf{7 0 0}$ ilustrações. São Paulo: Melhoramentos, 1994. p. 83.

CHEVALIER, Jean; GHEERBRANT, Alain. Trono pedestal. In:. Dicionário de símbolos: mitos, sonhos, costumes, gestos, formas, figuras, cores, números. 17. ed. Rio de Janeiro: J. Olympio, 2002. P 911.

CIRLOT, Juan-Eduardo. Dicionário de Símbolos. Trad.: Rubens Eduardo Ferreira Silva. São Paulo: Centauro, 1984.

COSTA, Sérgio Roberto. Dicionários de textuais. Belo Horizonte: Autêntica Editora, 2009.

NACIMENTO, Ilderlândio Assis de Andrade. O discurso citado: esquemas de apreensão e transmissão do discurso de outrem. In: NACIMENTO, Ilderlândio Assis de Andrade. A autoria em monografias de conclusão de curso de Letras: uma abordagem enunciativa. 2015. 141 f. Dissertação (Mestrado em Linguística), Universidade Federal da Paraíba, João Pessoa, 2015. p. 18 - 52.

OLIVEIRA, Antonio Flávio Ferreira de. Teoria Dialógica da Linguagem: categorias e conceitos. In: OLIVEIRA, Antonio Flávio Ferreira de. A entonação avaliativa na defesa criminal no Tribunal do Júri: contribuições da Teoria Dialógica da Linguagem. 2015. 114 f. Dissertação (Mestrado em Linguística), Universidade Federal da Paraíba, João Pessoa, 2015. p. 42 - 60. 
PONZIO, Augusto. A concepção bakhtiniana do ato como dar um passo. In: BAKHTIN, Mikhail M. Para uma filosofia do ato responsável. São Carlos - SP: Pedro \& João, 2010. p. 9 - 38.

VOLÓCHINOV, Valentin. Marxismo e filosofia da linguagem: problemas fundamentais do método sociológico na ciência da linguagem. Grillo, Sheila; Américo, Ekaterina Vólkova. Grillo, Sheila. São Paulo: Editora 34, 2017.

Recebido em: 30/11/2019

Aceito em: 09/03/2020 